Revista lus et Praxis, Año 25, № 3, 2019, pp. 277 - 306

ISSN 0717 - 2877

Universidad de Talca - Facultad de Ciencias Jurídicas y Sociales

El acceso a la justicia en el sistema interamericano de protección de los derechos humanos

Gerardo Bernales Rojas

Trabajo recibido el 6 de noviembre de 2018 y aprobado el 4 de julio de 2019

\title{
El acceso a la justicia en el sistema interamericano de protección de los derechos humanos
}

\author{
ACCESS TO JUSTICE IN THE INTER-AMERICAN \\ PROTECTION SYSTEM OF HUMAN RIGHTS
}

Gerardo Bernales Rojas*

\begin{abstract}
RESUMEN
El acceso a la justicia ha sido reconocido y desarrollado por la doctrina como derecho fundamental, a pesar de no existir un reconocimiento expreso como tal. La Convención Americana de Derechos Humanos ha sido la principal fuente normativa y la jurisprudencia de la Corte Interamericana de Derechos Humanos es la que lo ha reconocido como derecho fundamental, ubicándolo en los artículos $8^{\circ}$ y 25 , con relación al artículo 1.1, de la Convención, y a la vez lo ha ido dotando de contenidos, desarrollándolo más allá del área penal y aplicándolo a todas las áreas, al considerarlo como el derecho de los derechos.
\end{abstract}

\section{ABSTRACT}

Access to justice has been recognized and developed by the doctrine as a fundamental right, although there is no express recognition as such. The American Convention on Human Rights has been the main normative source, and the jurisprudence of the Inter-American Court of Human Rights is the one that has recognized it as a fundamental right, placing it in Articles 8 and 25, in relation to Article 1.1 of the Convention, and at the same time it has been providing content, developing beyond the criminal area, but applicable to all areas, considered as the right of rights.

PALABRAS CLAVES

Acceso a la justicia, derechos fundamentales, Corte Interamericana de Derechos Humanos.

KEYWORDS

Access to justice, fundamental rights, Inter-American Court of Human Rights.

\section{Introducción}

El acceso a la justicia es un derecho recurrente en la temática de los derechos fundamentales, especialmente respecto de grupos en situación de vulnerabilidad. Como expresa Cançado, "... acceso a la justicia no es, pues, sólo acceso a la prestación jurisdiccional, sino asimismo acceso al derecho"11, un imperativo

\footnotetext{
* Abogado por la P. U. Católica de Chile; magíster en Derecho, Mención Derecho Público, por la U. de Chile, y doctor en Derecho por la U. de Talca. Correo electrónico: gbernalesr1@gmail.com

1 CAnçAdo (2012), pp. 11 y 12.
} 
tanto en el plano nacional como internacional ${ }^{2}$. Es el principal derecho, el más importante de los derechos humanos ${ }^{3}$; el derecho fundamental de justicia pronta y cumplida 4 , "la interdicción de la indefensión" $n^{5}$.

Sin embargo, y a pesar de su relevancia, dicho derecho no ha sido reconocido expresamente dentro de los catálogos de derechos fundamentales ni en las cartas constitucionales, pactos o convenciones internacionales ${ }^{6}$, lo cual plantea la dificultad de no tener una concreción expresa del concepto y su contenido.

Por lo anterior, y a pesar de no tener un reconocimiento formal, el acceso a la justicia es un derecho fundamental independiente del debido proceso ${ }^{7}$ y cuyo contenido viene dado por los criterios y estándares emanados de la jurisprudencia de la Corte Interamericana de Derechos Humanos ${ }^{8}$, la cual ha sido fructífera en la materia, permitiendo con ello un mejor resguardo de los derechos fundamentales, con una interpretación bajo los principios "favor persona" y "progresividad".

En nuestro continente, la fuente normativa es la Convención Americana sobre Derechos Humanos ${ }^{9}$ y la doctrina que emana de ella, la que es complementada e interpretada por la jurisprudencia de la Corte IDH. Dicha jurisprudencia, a través de los principios y estándares que establecen sus decisiones, le entrega contenido concreto, permitiendo una aplicación más eficaz de la CADH, la que se ha ido desarrollando, primero, a partir de los votos minoritarios de su jurisprudencia, que, con el tiempo, se transformaron en doctrina mayoritaria, reconociendo el acceso a la justicia como derecho fundamental y dotándolo de contenido, y fijando los principios y estándares de interpretación general de la Corte IDH para la aplicación de la CADH.

${ }^{2}$ Cançado (2013), p. 231. En el mismo sentido, Helen Ahrens señala que el acceso a la justicia es "... un principio general de derecho internacional, que se convierte en un derecho dentro del Sistema Interamericano como expresión de una tutela multinivel de los derechos fundamentales...". AHRENS et al. (2015), p. 11.

3 Cappelletti y Garth (1983), p. 22.

${ }^{4}$ ROJAS (2011), p. 186.

${ }^{5}$ VALLESPIN (2002), p. 69.

${ }^{6}$ Excepción es la Carta de Ecuador, que lo reconoce formalmente en art. 75: “Toda persona tiene derecho al acceso gratuito a la justicia y a la tutela efectiva, imparcial y expedita de sus derechos e intereses...".

7 "Conjunto de derechos que tienen por finalidad asegurar que las pretensiones de las partes sean adecuadamente consideradas por el órgano llamado a tomar una decisión sobre las mismas", concepto dado por los profesores Luis Iván Díaz y Patricia Urzúa, siguiendo los criterios de la Corte Interamericana de Derechos Humanos. Díaz y Urzúa (2018), pp. 183-184.

${ }^{8}$ En adelante, Corte IDH.

${ }^{9}$ En adelante, $\mathrm{CADH}$. 
El acceso a la justicia nace del debido proceso y se desarrolla luego en aquellos aspectos que están en la periferia de las garantías procesales, las cuales, si bien son un elemento esencial del acceso a la justicia, no son el único.

Cuando el acceso a la justicia toma un camino propio, se entendió como el acceso a los tribunales de justicia, a la jurisdicción. De ahí evoluciona a un proceso con las debidas garantías procesales y comienza a hacerse patente también la necesidad de materializar o ejecutar lo que en el ámbito jurisdiccional se dictamine. Esto plantea la idea de que el debido proceso, junto con necesitar de las vías de acceso a él, también requiere la posibilidad de hacer cumplir lo resuelto. Así, se distinguen tres etapas; el acceso, el proceso con todas las garantías, y el cumplimiento fiel y oportuno de la sentencia.

Finalmente, el acceso a la justicia se desarrolla fuertemente en las ideas de búsqueda de una justicia eficiente y oportuna, especialmente respecto de los Ilamados grupos en situación de vulnerabilidad, lo que implica generar las condiciones necesarias para la obtención de una justicia material, una justicia efectiva, eliminando las barreras de acceso; como la asistencia jurídica a los pobres, de los sistemas judiciales en sí, de la representación de intereses difusos, los problemas medioambientales ${ }^{10}$, los costos del litigio, la excesiva duración de los procesos, las dificultades que presentan las Ilamadas "pequeñas causas"11, la existencia de obstáculos para permitir la legitimación activa en un proceso, el no reconocer el derecho de petición como derecho fundamental para la tutela de derechos e intereses, y los problemas de participación de los afectados o interesados en el sistema, sea por falta de conocimiento de los derechos y mecanismos para tutelarlos, o bien por problemas económicos ${ }^{12}$; en síntesis, el acceso a la justicia es "... el derecho a la propia realización de la justicia..."13.

El presente artículo analizará los antecedentes generales del acceso a la justicia, que nos permitirán definir de qué derecho hablamos (y a la vez nos permitirán identificarlo respecto del debido proceso). Luego revisaremos cómo se configura su contenido por la jurisprudencia de la Corte IDH, identificando el período previo a 2006. A continuación revisaremos la evolución de los criterios y estándares fijados por dicha jurisprudencia en dos períodos: 2006-2010 y 2011-2017.

Así, la pregunta que pretendemos responder con el presente trabajo es si la jurisprudencia de la Corte IDH ha reconocido formalmente, y dotado de contenido, al derecho de acceso a la justicia, como derecho fundamental de las personas.

\footnotetext{
10 Cappelletti y Garth (1983), pp. 38-178.

11 BrenNa (2006), pp. 165-167.

12 Gozaini (2006), pp. 168-185.

13 CANÇADo (2012), pp. 298-299.
} 


\section{El acceso a la justicia: Antecedentes generales}

Cappelletti y Garth expresan que no es fácil definir qué es el acceso a la justicia, y refieren un principio fundamental de todo sistema jurídico: "... que el pueblo pueda ejercer sus derechos y/o solucionar sus conflictos por medio del Estado...", lo que implica dos cosas, primero que el sistema legal sea igualitariamente accesible a todos y, segundo, que el sistema legal esté encaminado a que su funcionamiento sea individual y socialmente justo ${ }^{14}$. Es decir, como señala Marabotto, lograr que la brecha entre la norma y la realidad sea lo más pequeña posible implica alcanzar un mejor acceso a la justicia ${ }^{15}$.

La verdadera evolución pasó por la preocupación ya no sólo por la libertad, sino también por la igualdad, donde el sistema judicial constituye la última barrera o "... frontera donde los ciudadanos perciben si sus derechos son efectivamente respetados y garantizados, de ahí la imperiosa necesidad de facilitar y favorecer no sólo el acceso a la Justicia, sino un acceso efectivo a la misma..."16.

En este último sentido", la Corte IDH ha señalado que los "... Estados pueden y deben establecer presupuestos y criterios de admisibilidad de recursos internos, de carácter judicial o de cualquier otra índole..."18. Así, es obligatorio, para el Estado parte de la CADH, establecer mecanismos que aseguren el acceso a la justicia y también que este acceso no se limite sólo a lo jurisdiccional, admitiendo otros mecanismos, aun fuera de los órganos judiciales.

Aguilar señala que el acceso a la justicia es un concepto amplio, que puede ser abordado desde una doble perspectiva: "Desde un punto de vista más formal, stricto sensu, el acceso a la justicia suele ser reducido a exigencias adjetivas o procesales (...) enlistando una serie de requisitos procesales o que rodean la actividad procesal, y que deberían ser cumplidos para que el justiciable tenga acceso a la justicia (...). Por otra parte, desde una perspectiva más amplia, lato sensu, y de real relevancia en el mundo del siglo XXI, es que los individuos, comunidades y pueblos reclaman sus derechos, en sentido material, para que se haga real justicia (...). El acceso a la justicia lato sensu destaca el reconocimiento de los derechos de los individuos, comunidades y pueblos para poder, de esta manera, reivindicarlos ante un juez. El acceso a la justicia no es, pues, solo acceso a la prestación jurisdiccional sino asimismo acceso al derecho" ${ }^{\prime 19}$.

${ }^{14}$ Cappelletti y Garth (1983), p. 18.

15 Marabotto (2003), p. 293.

16 Greif (2014), pp. 56 y 57.

17 Maurino (2016), p. 913.

18 Sentencia Corte IDH, "Trabajadores Cesados del Congreso vs. Perú", 24 noviembre de 2006. Serie C No $158, C 126$.

${ }^{19}$ Cançado (2012), pp. 11 y 12. 
Cançado indica que el derecho de acceso a la justicia "no se reduce al acceso formal, stricto sensu, a la instancia judicial (tanto interna como internacional), sino comprende, además, el derecho a la prestación jurisdiccional, y encuéntrase subyacente a disposiciones interrelacionadas de la Convención Americana (como los artículos 25 y 8), además de permear el derecho interno de los Estados Partes. El derecho de acceso a la justicia, dotado de contenido propio, significa, lato sensu, el derecho a obtener justicia. Configúrase, así, en suma, como el derecho a la propia realización de la justicia" ${ }^{20}$.

García entiende el acceso a la justicia como un requisito necesario para la tutela efectiva de los derechos, una exigencia para que los otros derechos sean practicables, un requisito de vitalidad de facultades, libertades y prerrogativas ${ }^{21}$.

Gómez ubica el acceso a la justicia fuera de la lógica jurídica, como una noción ideológica contingente, cuyo concepto va cambiando ${ }^{22}$, según la materia, lugar y momento histórico. Es un concepto ideológico y sociológico, donde la idea central es que el acceso a la justicia se centra en "... la preocupación de que los justiciables puedan llegar a ser oídos y atendidos eficazmente por los órganos de impartición de justicia, sin dilaciones, sin trabas burocráticas, sin candados ni obstáculos económicos, y sin prejuicios raciales ni discriminaciones políticas, sexuales, religiosas o de otro género..." ${ }^{\prime 23}$.

Agrega Nogueira que "el derecho a la jurisdicción constituye un instrumento de defensa que el Estado pone en manos de las personas en reemplazo de la autotutela, esta última inaceptable dentro del Estado Constitucional y del Estado de Derecho, lo que obliga a configurarlo de manera que se establezca en su favor el mayor grado de garantías posibles"24. "... Constituye, en última instancia, uno de los pilares básicos no sólo de la Convención Americana, como del propio Estado de Derecho en una sociedad democrática (en el sentido de la Convención). Su correcta aplicación tiene el sentido de perfeccionar la administración de justicia a nivel nacional, con los cambios legislativos necesarios a la consecución de este propósito" ${ }^{\prime 25}$, es decir, la eficacia es el elemento central.

Para Ramos, el acceso a la justicia significa que "la justicia debe ser abierta por igual a todos, sin barreras discriminatorias de ningún tipo, ya sean económicas,

20 CANÇADO (2012), pp. 297-298.

${ }^{21}$ García (2012), p. 237.

${ }^{22}$ Misma opinión tiene el profesor Jorge Marabotto: el concepto de acceso a la justicia ha variado "... conforme a las ideas imperantes en cada determinada época del desarrollo de la humanidad". Marabotto (2003), p. 292.

${ }^{23}$ Gómez (2006), p. 353.

${ }^{24}$ Nogueira (2012), pp. 30-31.

${ }^{25}$ Cançado (2012), pp. 257-258. 
culturales, ideológicas, religiosas, étnicas, de ubicación geográfica, o incluso lingüísticas" 26 .

Bordalí ha señalado que el "... derecho de acceso a la justicia comporta la exigencia de abrir la puerta de los tribunales a todo tipo de derecho o interés que pueda requerir de tutela estatal (...). No cabe reconocer un derecho o interés y, luego, negarle el acceso al poder judicial a quien lo afirma" ${ }^{\prime 27}$. Y agrega que el derecho de acceso a la justicia incluye el derecho "... de solicitar la apertura y sustanciación de un proceso y a participar, en condiciones de igualdad, en los trámites del mismo..."28.

Vallespin conceptúa el derecho a la tutela judicial efectiva como "el derecho de acceso a los órganos jurisdiccionales para la obtención de una sentencia motivada y fundada en Derecho, a ser posible sobre el fondo, que con todos los efectos de la cosa juzgada ponga fin al litigio, y en su caso, para su ejecución" 29 .

Díaz señala que el acceso a la justicia es un tema que "... se presenta dentro de una problemática más amplia, que atiende a la efectividad de los derechos..." ${ }^{\prime \prime}$; es decir, el acceso a la justicia atiende a la necesidad de que los derechos reconocidos y garantizados por los Estados tengan eficacia material, real y concreta. Así, es "... el derecho de los ciudadanos de utilizar los mecanismos y estructuras judiciales instituidas por el Estado para la defensa y el ejercicio de sus derechos" ${ }^{\prime 31}$.

Así, el acceso a la justicia, cualquiera sea la denominación que le demos, tiene un origen difuso que impide, como en general con todas las instituciones, establecer un único contexto y una única conceptualización como punto de partida.

\section{Configuración jurisprudencial del acceso a la justicia por la Corte IDH}

El análisis jurisprudencial del acceso a la justicia nos permitirá darle un contenido sistemático, ya que doctrinariamente no lo tiene ${ }^{32}$. Y, para hacerlo, en este párrafo veremos la evolución que hay del acceso a la justicia desde la doctrina de la conexión de los artículos $8^{\circ}$ y 25 de la CADH, hasta la doctrina de la complementariedad e integración de ambas normas, lo que permite establecer el desarrollo del acceso a la justicia como derecho, el que, a partir de 2006,

\footnotetext{
26 Ahrens et al. (2015), p. 57.

27 Bordalí (2016), p. 187.

28 Bordalí (2011), p. 328.

29 VALLESPIN (2002), p. 69.

30 DíAz (2006), p. 157.

31 DíAz (2006), pp. 160 y 161.

32 Con la excepción de magistrados como Cançado o García, o autores como Larsen, Espejo y Leiva, quienes hacen un esfuerzo de sistematización plasmado en textos bibliográficos. CANÇADO (2012), pp. 79574; García (2012), pp. 25-359; Larsen (2016), pp. 423-434; Espejo y Leiva (2012), pp. 317-398 y $607-624$.
} 
tiene una evolución más sistemática y lo reconoce como derecho fundamental autónomo, dotado de contenido propio y en franca evolución.

La fuente normativa a la que recurre la Corte $\mathrm{IDH}^{33}$ es la $\mathrm{CADH}$, siendo la norma pertinente al acceso a la justicia el artículo $8^{\circ}$ de dicha convención; al menos así lo plantea Ibáñez. El acceso a la justicia se entiende por la propia Corte "... como una 'norma imperativa de Derecho Internacional', (que) no se agota ante el hecho de que se tramiten los respectivos procesos internos, sino que exige que el Estado garantice que estos aseguren, en un tiempo razonable, la satisfacción de los derechos que tienen las partes en el mismo...". ${ }^{34}$, teniendo como base de tal afirmación las sentencias de la Corte IDH del "caso Bulacio"35-36 y del "caso Palamara" ${ }^{\prime 37}$. Agrega Ibáñez que los Estados "... no deben imponer trabas a las personas que acudan a los jueces o tribunales en busca de que sus derechos sean determinados o protegidos...", a la vez que el Estado tiene el deber de consagrar normativamente y asegurar la debida aplicación de las garantías del debido proceso a las personas frente a actos que violen sus derechos fundamentales $^{38}$, citando como fundamento jurisprudencial los casos "Cantos"39, "Baena Ricardo y otros" ${ }^{40}$ y "Mohamed" ${ }^{\prime 4}$. Concluye que las garantías procesales a que se refiere el artículo $8^{\circ}$ de la CADH van en la línea del amplio derecho de acceso a la justicia, regulando la forma en que dicha justicia debe impartirse, dejando para el artículo 25 de la convención citada lo relativo al derecho al recurso ${ }^{42}$, y

\footnotetext{
${ }^{33}$ La evolución de la protección a los derechos fundamentales ha sido de la mano de la jurisprudencia de la Corte IDH. Hoy se reconoce un sistema interamericano de protección de los derechos humanos y, a la vez, forma parte de éste el derecho constitucional de los Estados, lo cual ofrece nuevas posibilidades, que van más allá de los clásicos problemas derivados de los crímenes de lesa humanidad, y evoluciona hacia el reconocimiento de un mayor contenido a los derechos o, directamente, reconociendo nuevos derechos. CONTESSE (2010), pp. 198 y 199. Así, hay un enorme avance en la protección de los derechos laborales desarrollado a partir de la jurisprudencia de la Corte IDH, particularmente a partir de la sentencia del Caso Baena, Ricardo y otros vs. Panamá, CANESSA (2014), p. 21.

34 IBÁÑ̃ez (2014), p. 213.

35 Sentencia Corte IDH, "Bulacio con Argentina", 18 de septiembre de 2003, C 114.

36 LARSEN (2016), p. 426.

37 Sentencia Corte IDH, "Palamara contra Chile", 22 de noviembre de 2006, C 188.

38 IBÁÑ̃ez (2014), p. 213.

39 Sentencia Corte IDH, "Cantos vs. Argentina", 28 de noviembre de 2002, C 50.

40 Sentencia (competencia) Corte IDH, "Baena Ricardo y otros vs. Panamá", 28 de noviembre de 2003, C 79.

${ }^{41}$ Sentencia Corte IDH, "Mohamed vs. Argentina", 23 de noviembre de 2012, C 83.

42 IBÁÑ̃ez (2014), p. 213.
} 
cita como fundamento de dicha conclusión un voto parcialmente disidente de la jueza Cecilia Medina ${ }^{43}$.

En nuestro parecer, si bien concordamos en que en el artículo $8^{\circ}$ de la CADH encontramos el reconocimiento del derecho de acceso a la justicia, no compartimos la idea de que ella corresponda solo a ese artículo, sino que dicho artículo pierde sentido si a la vez no existe el recurso efectivo a los tribunales, derecho consagrado en el artículo 25 de la $\mathrm{CADH}$, debiendo existir una integración y complementación entre ambos, para hablar del derecho de acceso a la justicia en su amplia dimensión. Quien plantea de mejor modo esta postura es el magistrado Cançado ${ }^{44}$, quien señala que entre el derecho al recurso del artículo 25 y las garantías del debido proceso legal existe una relación indisoluble, la cual se extiende al derecho a la fiel ejecución de la sentencia, lo cual constituye un complemento para el Estado de derecho de una sociedad democrática, lo que queda de manifiesto en diversas causas o procesos ${ }^{45}$, teniendo una concreción en la Opinión Consultiva $N^{0} 16^{46}$. Así, recurre al párrafo $50^{47}$ del fallo "Cantos", también citado por Ibáñez, para indicar que el artículo $8^{\circ}$ de la citada CADH contemplaba o reconocía el derecho de acceso a la justicia, dejando el artículo 25 de la misma convención para el derecho al recurso, agregando Cançado que, junto a ese párrafo, está el párrafo $52^{48}$ del aludido fallo, para indicar que también el artículo 25 de la convención aludida consagra el derecho de acceso a la justicia ${ }^{49}$.

${ }^{43}$ Sentencia Corte IDH, "Hermanos Gómez Paquiyauri vs. Perú", 8 de julio de 2004, voto parcialmente disidente de jueza Cecilia Medina, C 2.

${ }^{44}$ Cançado (2012), pp. 280-284.

45 CANÇAdo (2012), p. 284.

46 Opinión Consultiva OC 16/99, 1 de octubre de 1999, sobre el "Derecho a la Información sobre la Asistencia Consular en el Marco de las Garantías del Debido Proceso Legal", párrafo 119.

47 “50. Según el artículo 8.1 de la Convención [t]oda persona tiene derecho a ser oída, (...).

Esta disposición de la Convención consagra el derecho de acceso a la justicia. De ella se desprende que los Estados no deben interponer trabas a las personas que acudan a los jueces o tribunales en busca de que sus derechos sean determinados o protegidos. Cualquier norma o medida del orden interno que imponga costos o dificulte de cualquier otra manera el acceso de los individuos a los tribunales, y que no esté justificada por las razonables necesidades de la propia administración de justicia, debe entenderse contraria al precitado artículo 8.1 de la Convención".

48 "52. El artículo 25 de la Convención también consagra el derecho de acceso a la justicia (...). [L] a garantía allí consagrada se aplica no sólo respecto de los derechos contenidos en la Convención, sino también de aquéllos que estén reconocidos por la Constitución o por la ley (...). [Y] que para que el Estado cumpla con lo dispuesto en el artículo 25 de la Convención no basta con que los recursos existan formalmente, sino que los mismos deben tener efectividad, es decir, debe brindarse a la persona la posibilidad real de interponer un recurso que sea sencillo y rápido. Cualquier norma o medida que impida o dificulte hacer uso del recurso de que se trata constituye una violación del derecho al acceso a la justicia, bajo la modalidad consagrada en el artículo 25 de la Convención Americana".

49 Sentencia Corte IDH, "Cantos vs. Argentina", 28 de noviembre de 2002, C 52. 
Larsen $^{50}$ agrega el párrafo $55^{51}$, que permite hablar de la complementariedad de las normas de los artículos $8^{\circ}$ y 25 de la CADH. Y, por nuestra parte, estimamos que la idea queda completa con la integración de los párrafos 57, 60 y 62 del aludido fallo ${ }^{52}$.

\subsection{La conexión de los artículos $8^{\circ}$ y 25 de la CADH como fuentes originarias del derecho de acceso a la justicia}

Si bien se ha planteado nuestra adhesión a lo señalado en el sentido de que a partir del año 2002 la Corte IDH viene en la línea de considerar a los dos artículos, el $8^{\circ}$ y el 25 de la CADH, como la fuente del derecho de acceso a la justicia y no sólo al artículo $8^{\circ}$, existen antecedentes previos, manifestados en la jurisprudencia de esa Corte, que indicaban que este criterio de interpretación de la Corte IDH se venía formulando.

En el caso "Niños de la calle", o caso "Villagrán Morales y otro", se expresaba con claridad de que la percepción del caso, es decir, del análisis de una denuncia de la violación de la normativa de la $\mathrm{CADH}$, debe ser integral, lo que obliga al análisis conjunto del artículo $8^{\circ}$ y 25 de la aludida convención, ya que el estándar exigido por ella no se mira individualmente para cada norma; es un estándar global, es el estándar de la CADH y no de artículo determinado ${ }^{53}$.

${ }^{50}$ LARSEN (2016), p. 434.

51 "55. Este Tribunal estima que para satisfacer el derecho de acceso a la justicia no basta que en el respectivo proceso se produzca una decisión judicial definitiva. También se requiere que quienes participan en el proceso puedan hacerlo sin el temor de verse obligados a pagar sumas desproporcionadas o excesivas a causa de haber recurrido a los tribunales"....

52 "57. La otra cuestión debatida en estas actuaciones (...) es la de si el procedimiento se ha ajustado a los artículos $8^{\circ}$ y 25 de la Convención Americana en cuanto garantizan el derecho a una respuesta de la autoridad judicial dentro de un plazo razonable (...)".

(...) 60. En el caso subjudice, la Corte observa que la aplicación de la tasa judicial y los honorarios de acuerdo a los parámetros permitidos por la ley condujeron a que se cobraran sumas exorbitantes, con el efecto de obstaculizar el acceso del señor Cantos a la justicia (...). Ante esta situación, las autoridades judiciales han debido tomar todas las medidas pertinentes para impedir que se produjese esa situación, y para lograr que se hicieran efectivos el acceso a la justicia y el derecho a las garantías judiciales y a la protección judicial (...).

62. (...). Así las cosas, este Tribunal no encuentra fundamento para considerar que el Estado ha incumplido el artículo $2^{\circ}$ de la Convención porque su orden jurídico, considerado en su integridad, no lleva necesariamente a impedir el acceso a la justicia. En todo caso sería aconsejable que el Estado suprimiera de su ordenamiento jurídico las disposiciones que pudiesen dar lugar, de una u otra manera, a la imposición de tasas de justicia y al cálculo de honorarios que, por ser desmedidas y excesivos, impidieran el cabal acceso a la justicia"....

53 Sentencia Corte IDH, "Niños de la Calle (Villagrán Morales y otros) vs. Guatemala", 19 de noviembre 1999, C 224, 225, 226 y 234. 
En el caso de "Durand Ugarte" se expresaba que la falta de garantías mínimas, necesariamente lleva a la falta de efectividad del recurso, vinculando el artículo $8^{\circ}$ con el 25 de la $\mathrm{CADH}^{54}$.

En el caso "Bámaca Velásquez", señalaba que esta visión integradora de las normas del debido proceso legal y el derecho al recurso, no sólo la reconoce la CADH y la Corte IDH, sino que también por la Corte Europea de Derechos Humanos $^{55}$.

Esta indisociabilidad de las normas queda de manifiesto también en el "caso Las Palmeras", donde se expresa que podemos encontrar en el artículo $8^{\circ}$ de la $\mathrm{CADH}$ la norma que reconoce el derecho de acceso a la justicia, y también en el artículo 25 de la misma; donde los párrafos 54 y 65 expresan que: "54. En conclusión, la aplicación de la jurisdicción militar en este caso no garantizó el debido proceso en los términos del artículo 8.1 de la Convención Americana, que regula el derecho de acceso a la justicia de los familiares de las víctimas del caso". Y al concluir, en el párrafo 65 se señala que: "65. En consecuencia, el artículo 8.1 de la Convención Americana, en conexión con el artículo 25.1 de la misma, confiere a los familiares de las víctimas el derecho a que la muerte de estas últimas sea efectivamente investigada por las autoridades del Estado; se siga un proceso contra los responsables de estos ilícitos; en su caso se les impongan las sanciones pertinentes, y se reparen los daños y perjuicios que dichos familiares han sufrido" ${ }^{\prime 56}$.

La conexión entre ambos derechos de la CADH es lo que permite dar efectividad al acceso a la justicia.

\subsection{Jurisprudencia de la Corte IDH avanza a la doctrina de complementariedad e integración de los artículos $8^{\circ}$ y 25 de la CADH, con relación al derecho de acceso a la justicia}

Como ya se ha señalado, la complementariedad ${ }^{57}$ e integración de los artículos $8^{\circ}$ y 25 de la $\mathrm{CADH}$ tienen un carácter indisociable, como lo señala el magistrado Cançado, el cual se ha ido dando de forma progresiva en el tiempo, lo que calificó

\footnotetext{
${ }^{54}$ Sentencia Corte IDH, "Durand y Ugarte vs. Perú", 16 de agosto 2000, C 120, 121, 129 y 130.

55 Sentencia Corte IDH, "Bámaca Velásquez vs. Guatemala", 25 de noviembre de 2000, C 187, 189 y 191.

${ }^{56}$ Sirven de antecedente para entender esta relación los C 58, 60 y 61.

${ }^{57}$ Como recuerdan los profesores Arias y Galindo, el principio de complementariedad solo opera ante la ineficacia de los sistemas nacionales. ArIAS y GaLINDO (2015), p. 28.
} 
como un avance jurisprudencial intangible ${ }^{58}$, constituyendo un todo orgánico que conforma "... el Rule of Law en una sociedad democrática"159.

Un primer caso es el de "Sánchez versus Honduras", que exige a los Estados asegurar el libre y pleno ejercicio de los derechos humanos, con pleno acceso y capacidad a los familiares para actuar en las investigaciones, lo que constituye un reconocimiento del derecho de acceso, en el plano de la investigación penal, invocando las normas de forma integrada, tanto la del artículo $8^{\circ}$ como la del artículo $25^{60}$.

Por otro lado, si bien no hay un reconocimiento expreso a este derecho de acceso a la justicia de forma integral y complementaria de los artículos $8^{\circ}$ y 25 de la CADH, como expresan Espejo y Leiva "... (e)I derecho de acceso a la justicia requiere que se haga efectiva la determinación de los hechos que se investigan y, en su caso, de las correspondientes responsabilidades penales en tiempo razonable, por lo que, en atención a la necesidad de garantizar los derechos de las personas perjudicadas, una demora puede llegar a constituir, por sí misma, una violación de las garantías judiciales. Además, por tratarse de una desaparición forzada, el derecho de acceso a la justicia incluye que se procure determinar la suerte o paradero de la víctima..." ${ }^{61}$. Para los autores, hay acceso a la justicia cuando se exige, además del debido proceso (artículo $8^{\circ}$ de la $\mathrm{CADH}$ ), una tutela judicial efectiva y cuando existe derecho al recurso (artículo 25 de la convención), conclusión que queda clara cuando dichos autores citan el párrafo 114 del caso "Bulacio", que exige evitar dilaciones indebidas que conduzcan a la impunidad ${ }^{62}$.

Otro caso relevante es el de "Myrna Chang", donde el ocultamiento de hechos, la impunidad y la obstrucción de la justicia mediante la amenaza de quienes podían aportar al proceso configuran en definitiva una denegación del acceso a la justicia ${ }^{63}$. La misma consideración quedó expresamente señala en la sentencia de los casos "19 Comerciantes" "64, "Comunidad Moiwana" 65 y "Masacre Mapiripán"66.

Así, podemos señalar que, al año 2005, la consagración del derecho de acceso a la justicia se plasma, de forma integral, en esta complementariedad e integración

\footnotetext{
58 CANÇADO (2012), p. 289.

59 CANÇADO (2012), p. 291.

60 Sentencia Corte IDH, "Juan H. Sánchez versus Honduras", 7 de junio de 2003, C 137 y 186.

61 Espejo y Leiva (2012), pp. 395, 396.

62 Sentencia Corte IDH, "Bulacio con Argentina", 18 de septiembre de 2003, C 114 y 115.

63 Sentencia Corte IDH, "Myrna Mack Chang vs. Guatemala", 25 de noviembre 2003, C 216 y 217.

64 Sentencia Corte IDH, "19 Comerciantes vs. Colombia", 5 de julio de 2004, C 173, 188.

65 Sentencia Corte IDH, "Comunidad Moiwana vs. Suriname", 15 de junio 2005, C 163, 164.

66 Sentencia Corte IDH, "Masacre de Mapiripán" vs. Colombia, 15 septiembre de 2005, C 211.
} 
que debe darse necesariamente a los artículos $8^{\circ}$ y 25 de la $\mathrm{CADH}$, como lo ha señalado y fundamentado el magistrado Cançado, agregándose a las referencias ya indicadas la alusión que hace Cançado al "Caso Hilaire, Constantine y Benjamín y otros $^{\prime \prime 67}$, que motiva con base en la Opinión Consultiva OC- 16/9968, cuando expresa que no hay un debido proceso legal "si un justiciable no puede hacer valer sus derechos 'en forma efectiva', es decir, si no tiene un verdadero derecho de acceso a la justicia" ${ }^{\prime \prime 9}$.

Para Cançado, el amplio alcance del derecho de acceso a la justicia "... no se reduce al acceso formal, stricto sensu, a la instancia judicial (tanto interna como internacional), sino comprende, además, el derecho a la prestación jurisdiccional, y encuéntrase adyacente a disposiciones interrelacionadas de la Convención Americana (como los artículos $8^{\circ}$ y 25), además de permear el derecho interno de los Estados Partes. El derecho de acceso a la justicia, dotado de contenido jurídico propio, significa, latu sensu, el derecho a obtener justicia. Configúrase, así, en suma, como el derecho a la propia realización de la justicia (...). Podemos aquí visualizar un verdadero derecho al Derecho, o sea, el derecho a un ordenamiento jurídico - a niveles tanto nacional como internacional- que efectivamente salvaguarde los derechos fundamentales de la persona humana"70.

\section{El derecho de acceso a la justicia y su evolución como derecho fundamental en la jurisprudencia de la Corte IDH a contar del año 2006}

El título anterior nos permitió conocer el estado en que se encontraba el reconocimiento del derecho de acceso a la justicia hasta 2005. Para ello se sintetizó la jurisprudencia, en donde se aprecia el reconocimiento de este derecho, comprendido dentro de los derechos a las garantías procesales y el derecho al recurso, consagrados en los artículos $8^{\circ}$ y 25 de la CADH, es decir, su reconocimiento como un derecho fundamental implícito en ambos artículos. Esto no es menor, pues el desarrollo jurisprudencial que hasta ese momento lo situaba por medio de una simple conexión entre ambos artículos, abarca mucho más de lo que formalmente es el debido proceso y, por ende, si abarca más allá, el debido proceso quedaría comprendido como parte del derecho de acceso a la justicia, y no al revés.

\footnotetext{
${ }^{67}$ Sentencia Corte IDH, caso "Hilaire, Constantine y Benjamín y otros vs. Trinidad y Tobago", 21 de junio de 2002.

${ }^{68}$ Opinión Consultiva OC 16/99, de 1 de octubre de 1999.

${ }^{69}$ CANÇADO (2012), p. 285.

${ }^{70}$ CANÇADO (2012), pp. 297 y 298.
} 
El gran déficit que presenta este reconocimiento es que es implícito, a pesar de las diversas manifestaciones expresas. Lo anterior no obsta a que, si bien reconocemos la falta del reconocimiento como derecho autónomo a nivel normativo, sí existe un reconocimiento como derecho fundamental a nivel jurisprudencial, ubicado en el ámbito de las aludidas normas jurídicas ${ }^{71}$.

Hecho este reconocimiento, se hace necesario establecer su contenido, para lo cual se dividirá, cronológicamente la jurisprudencia de la Corte IDH en dos periodos: desde 2006 hasta 2010 y desde 2011 hasta 2017.

\subsection{Estándares emanados de la jurisprudencia de la Corte IDH en el período 2006-2010 ${ }^{72}$}

Con la jurisprudencia estudiada, pueden establecerse criterios generales y criterios particulares para analizar el acceso a la justicia en la Corte IDH, jurisprudencia que efectivamente hace reconocimiento formal y expreso del derecho de acceso a la justicia.

Lo anterior no es una mera apreciación subjetiva nuestra. La evolución de la jurisprudencia ha ido en la línea de reconocer la existencia de este derecho y de darle un contenido propio cada vez más amplio; derecho que, además, se analiza de forma independiente del debido proceso y que se caracteriza por tener una configuración mucho más amplia, ya que va comprendido,

\footnotetext{
71 Barbero (2016), p. 215; CanÇAdo (2012), pp. 280-299; Espejo y Leiva (2012), pp. 395 y 396; García (2012), pp. 45-49; LARSeN (2016), pp. 256 y 434; Nogueira (2008), pp. 271-280.

72 Sentencias de la Corte IDH periodo 2006-2010: Caso La Masacre de Pueblo Bello contra Colombia; Caso de la sentencia López Álvarez contra Honduras; Caso de la sentencia Acevedo Jaramillo y otros con Perú; Caso de la Comunidad Indígena Sawhoyamaxa contra Paraguay; Caso de Baldeón García contra Perú; Caso de la sentencia Masacres de Ituango contra Colombia; Caso de la sentencia Ximenes Lopes contra Brasil; Caso Servellón García y otros con Honduras; Caso Goiburú y otros contra Paraguay; Caso Vargas Areco contra Paraguay; Caso Almonacid Arellano y otros contra Chile; Caso Trabajadores del Cesados del Congreso (Aguedo Alfaro y otros) con Perú; Caso del Penal Miguel Castro Castro con Perú; Caso La Cantuta contra Perú; Caso de la Masacre de La Rochela contra Colombia; Caso Zambrano Vélez y otros contra Ecuador; Caso Escué Zapata contra Colombia; Caso Cantoral Huamani y García Santa Cruz contra Perú; Caso Albán Cornejo y otros contra Ecuador; Caso Salvador Chiriboga contra Ecuador; Caso Yvon Neptune contra Haití; Caso Castañeda Gutman contra México; Caso Heliodoro Portugal contra Panamá; Caso Bayarri contra Argentina; Caso Valle Jaramillo y Otros contra Colombia; Caso Ticona Estrada y Otros contra Bolivia; Caso Kawas Fernández contra Honduras; Caso Escher y Otros contra Brasil; Caso Anzualdo Castro contra Perú; Caso Garibaldi contra Brasil; Caso Campo Algodonero contra México; Caso Usón Ramírez contra Venezuela; Caso Radilla Pacheco contra México; Caso Masacre de las Dos Erres; Caso Chitay Nech y Otros contra Guatemala; Caso Manuel Cepeda Vargas contra Colombia; Caso Fernández Ortega contra México; Caso Rosendo Cantú contra México; Caso Ibsen Cárdenas e Ibsen Peña contra Bolivia; Caso Vélez Loor contra Panamá; Caso Gomes Lund o "Guerrilha do Araguaia" contra Brasil; Caso Cabrera García y Montiel Flores contra México (42 fallos). Jurisprudencia de la Corte Interamericana de Justicia.
} 
por ejemplo, en expresiones como que "... los Estados deben abstenerse de realizar acciones que de cualquier manera vayan dirigidas, directa o indirectamente, a crear situaciones de discriminación de jure o de facto..." 173 , o bien cuando señala que la investigación de una violación de derechos humanos "... debe cumplirse con seriedad y no como una simple formalidad condenada de antemano a ser infructuosa, y debe tener un sentido y ser asumida por los Estados como un deber jurídico propio y no como una simple gestión de intereses particulares... ${ }^{174}$, solo por citar ejemplos de disposiciones amplias, que permiten extender su contenido.

En definitiva, los fallos de la Corte IDH analizados han señalado literalmente, de forma expresa, el concepto o idea de derecho de acceso a la justicia, sea en sus decisiones como tribunal o en los votos disidentes o concurrentes, y por ello es que señalamos que el derecho de acceso a la justicia, como tal, existe, ya que, más allá de que no se encuentre literalmente consagrado en la $\mathrm{CADH}$, sí se encuentra materialmente reconocido, tratado y desarrollado, asignándosele contenido, y se ha hecho exigible a los Estados al establecerse estándares y principios con relación a este derecho.

A.- En cuanto a criterios generales, el acceso a la justicia parte por señalar que tanto las víctimas como sus familiares deben tener acceso a la justicia, ya que no puede quedarse sólo en la víctima, porque en muchos casos la víctima está desaparecida o muerta, o bien impedida de ejercer sus derechos.

Un segundo aspecto general, y un objetivo propio del derecho de acceso a la justicia, es que este derecho busca impedir la impunidad ${ }^{75}$, apareciendo esto como un desafío concreto que debe ser alcanzado en la búsqueda de la justicia. Dicha impunidad involucra no sólo el efecto de no repetición de la conducta sancionada, lo cual constituye en sí otro desafío del derecho internacional humanitario, sino que busca también satisfacer las condiciones de justicia para las víctimas y sus familias; sanción a los responsables y reparación integral para ellos.

Otro aspecto general es la imposición al Estado de adoptar todas las medidas que sean necesarias para facilitar el acceso a la justicia y eliminar los

\footnotetext{
73 Sentencia Corte IDH, "Fernández Ortega y Otros vs. México", 30 de agosto de 2010, C 200.

${ }^{74}$ Sentencia Corte IDH, "Radilla Pacheco vs. Estados Unidos Mexicanos", 23 de noviembre de 2009, C 233 .

75 La impunidad es la "... ausencia, de iure o de facto, de la imputación de la responsabilidad penal de los autores de violaciones de los derechos humanos, así como de su responsabilidad civil, administrativa o disciplinaria, de modo de aquéllos escapan a toda investigación tendiente a permitir su imputación, su arresto, su juzgamiento y, en caso de reconocerse su culpabilidad, a su condena a penas apropiadas y reparar los perjuicios sufridos por sus víctimas". LARRANDART (2016), p. 152.
} 
obstáculos para ello. No se trata de pedirle una actividad concreta, sino que, como deber jurídico, se le impone la obligación de actuar de oficio o a petición de parte, de acuerdo a las necesidades puntuales que se vayan presentando.

También es un aspecto relevante que el recurso (en sentido amplio) sea efectivo, es decir, idóneo para alcanzar la solución del conflicto.

Un tema que es reiterado en esta materia es que todo proceso o investigación debe ser realizado en un plazo razonable; justicia que tarda no es justicia, y ello tiene efectividad en cuanto la actividad investigativa no se ve diluida en el tiempo, impidiendo que los sobrevivientes o familiares de una víctima puedan alcanzar una respuesta o ver un resultado.

Finalmente, un último criterio general que podemos señalar es la informalidad al momento de investigar; esto es, actuar eliminando los obstáculos para el acceso a la justicia, ya que ésta no puede quedar supeditada al formalismo o ritualismo (que si bien forma parte del debido proceso, no puede transformarse en obstáculo para alcanzar la justicia).

B.- Con relación a los criterios particulares, los estándares van de la mano con una extensión a temas que van más allá de lo procedimental, los que se enmarcan dentro del acceso a la justicia. En primer lugar, en lo relativo al plazo razonable, la ponderación de éste se hace con base en cuatro criterios: la complejidad del caso, la actividad de los interesados, la actividad de la autoridad judicial y la afectación generada en la situación jurídica de la persona involucrada en el proceso ${ }^{76}$.

Un segundo tópico es que la investigación debe ser capaz de esclarecer los hechos, determinar las sanciones que correspondieren y entregar una reparación ${ }^{77}$ integral a la víctima y a su familia. Así, los recursos existentes deben ser efectivos y serios, o sea, capaces de llegar a un resultado que satisfaga las exigencias de justicia que la comunidad internacional demanda en materia de derecho humanitario. Lo anterior implica que la actividad investigativa, por parte de las autoridades judiciales, debe ser diligente; es decir, adoptar todas las medidas pertinentes para aclarar los hechos e impedir la impunidad. Esta idea,

\footnotetext{
${ }^{76}$ Así lo ha dicho también Pita, quien señala que estos cuatro criterios los han utilizado tanto la Corte IDH como el Tribunal Europeo de Derechos Humanos, este último en el "Caso Rigeisen" de 16 de julio de 1971 y el "Caso G. S". de 21 de diciembre de 1999. Priori (2016), pp. 168-171.

77 El concepto de "reparación" es un concepto amplio. La mayoría de los fallos, por lo mismo, ocupa la expresión "reparación integral" para dejar abierta la mayor cobertura posible que la realidad del caso pueda requerir. Para Gozaíni, por reparación se comprenden las diversas las diversas formas y actuaciones, las que se clasifican en medidas de satisfacción y medidas de indemnización. Se conjugan tres factores para determinar las medidas de bienestar: la justicia, la no repetición de los hechos y el reconocimiento público de responsabilidad. Gozalnı (2016), p. 995.
} 
bastante amplia, significa que debe cumplirse con las exigencias del debido proceso y, dentro de ello, que han de adoptarse las medidas concretas para procurar las pruebas necesarias para el esclarecimiento de los hechos denunciados, como asimismo evitarse las dilaciones indebidas, jurisdicciones especiales y los excesivos recursos interpuestos con el solo afán de dilatar la investigación.

Otros criterios más puntuales son:

a.- En las desapariciones forzosas, la necesidad de establecer qué ocurrió con la víctima y, en lo posible, saber su paradero.

b.- En casos de migrantes, dar asistencia letrada gratuita; que la asesoría de intérprete sea desde las primeras actuaciones que precise la víctima, o en que se afecten los derechos de un imputado; contar con la información necesaria para la asistencia consular, y el Estado debe procurar lo indispensable para que, en consideración a factores sociales y culturales, no se genere una desigualdad en el trato ni una discriminación arbitraria.

c.- En el caso de comunidades indígenas, la protección efectiva implica tomar en cuenta las particularidades propias de dichas comunidades, ponderando los factores económicos y sociales, así como la situación de vulnerabilidad objetiva (educación, salud, economía, etc.) que puedan tener, junto a los factores que puedan producirse con relación al resto de la comunidad nacional. Es importante respetar su derecho consuetudinario y sus valores, usos y costumbres.

d.- Respecto de las víctimas de violencia sexual, particularmente las mujeres, hay un fallo ${ }^{78}$ que señala algunas condiciones que aseguran un acceso a la justicia de forma integral, atendida la naturaleza del derecho vulnerado: i) que la víctima declare en un ambiente cómodo y seguro, que brinde privacidad y confianza; ii) que el registro de la declaración de la víctima evite o limite la necesidad de su repetición; iii) que se entregue atención médica, sanitaria y psicológica a la víctima, desde la emergencia, y se mantenga continuadamente si se requiere; iv) que exista un protocolo de atención para reducir los efectos de la violación; v) que se realice examen médico y psicológico completo y detallado, examen que debe ser realizado por personal idóneo y capacitado, de inmediato o en tiempo oportuno (para constatar los daños y procurar medios de prueba si ello es posible), en lo posible, el examinador debe ser del sexo que la víctima indique (procurando disminuir al máximo las posibilidades de una revictimización con los exámenes), ofreciéndosele a la víctima, además, la posibilidad de que sea acompañada por alguien de su confianza si lo desea; vi) que se documenten y coordinen los actos investigativos y se maneje

\footnotetext{
${ }^{78}$ Sentencia Corte IDH, "Fernández Ortega y Otros vs. México", 30 de agosto de 2010, C 194.
} 
diligentemente la prueba, tomando muestras suficientes, realizando estudios para determinar la posible autoría del hecho, asegurando posibles pruebas como la ropa de la víctima, investigando la escena del crimen y garantizando la correcta cadena de custodia, y vii) que se brinde acceso a asistencia jurídica gratuita a la víctima durante todas las etapas del proceso.

De esta forma, en este período, y a partir del reconocimiento que ya existía previamente de este derecho (que daba cuenta de que el derecho de acceso a la justicia estaba reconocido en los artículos $8^{\circ}$ y 25 de la CADH), el acceso a la justicia alcanza un desarrollo importante y relevante, que lo va dotando de un contenido propio e independiente de cualquier otro derecho, que va más allá de lo relativo al debido proceso y donde, incluso, éste se ve como un derecho que forma parte del acceso a la justicia, por cuanto la labor de las autoridades judiciales debe ser aclarar los hechos denunciados, con respeto a las normas del debido proceso, y conteniendo otros derechos no formalmente reconocidos, como el derecho a la verdad o a la reparación a la víctima y a su familia.

\subsection{Estándares emanados de la jurisprudencia de la Corte IDH en el período 2010-2017 (agosto) ${ }^{79}$}

Al momento de analizar los estándares, surge una primera impresión, que es que el derecho al acceso a la justicia se desarrolla esencialmente entre los

\footnotetext{
79 Sentencias de la Corte IDH periodo 2011-2017 (agosto): Caso Gelman contra Uruguay; Caso Vera Vera contra Ecuador; Caso Chocrón Chocrón contra Venezuela; Caso Torres Millacura contra Argentina; Caso Contreras contra El Salvador; Caso Fleury contra Haití; Caso de la Familia Barrios contra Venezuela; Caso González Medina y Familiares contra República Dominicana; Caso Forneron e hija contra Argentina; Caso Furlan y Familiares contra Argentina; Caso Palma Mendoza y Otros contra Ecuador; Caso Velez Restrepo contra Colombia; Caso Uzcátegui contra Venezuela; Caso Masacres de Río Negro; Caso Nadege Dorzema contra República Dominicana; Caso Masacres de el Mozote y Lugares Aledaños; Caso Castillo González contra Venezuela; Caso García contra Guatemala; Caso Masacre de Santo Domingo contra Colombia; Caso Mémoli contra Argentina; Caso "Corte Suprema de Justicia" (Quintana Coello y otros); Caso García Lucero contra Chile; Caso Luna López contra Honduras; Caso Gutiérrez y Familia contra Argentina; Caso Osorio Rivera contra Perú; Caso Liakat Ali Alibux contra Suriname; Caso Véliz Franco y Otros contra Guatemala; Caso de los Hermanos Landaeta Mejías y Otros contra Venezuela; Caso Defensor de Derechos Humanos; Caso de los Pueblos Indígenas Kuna De Madungandí Y Emberá De Bayano; Caso Rochac Hernández contra El Salvador; Caso Desaparecidos del Palacio de Justicia; Caso Espinoza González contra Perú; Caso Cruz Sánchez contra Perú; Caso Canales Huapaya contra Perú; Caso Comunidad Campesina de Santa Bárbara contra Perú; Caso Galindo Cárdenas y Otros contra Perú; Caso Ruano Torres contra El Salvador; Caso García Ibarra y Otros contra Ecuador; Caso Velásquez Paiz y Otros contra Guatemala; Caso Maldonado Ordóñez contra Guatemala; Caso Trabajadores de la Hacienda Brasil Verde contra Brasil; Caso Valencia Hinojosa contra Ecuador; Caso I.V. contra Bolivia; Caso Vásquez Durand y Otros contra Ecuador; Caso Favela Nova Brasilia contra Brasil; Caso Acosta contra Nicaragua (47 fallos). Jurisprudencia de LA Corte InTeRAMericANA DE Justicia.
} 
años 2006 y 2010, periodo que es posterior a la salida del magistrado Cançado, gran impulsor del desarrollo de este derecho a nivel de la Corte IDH, y donde su influencia se hace sentir, pero en este segundo periodo, el desarrollo sistemático alcanzado se ve ampliado en cuanto a su temática general, mas con manifestaciones más concretas y puntuales, aplicadas a casos particulares; es decir, nuevos temas e ideas, aunque menos sistematización.

Así, en el primer período analizado, aparece este derecho en el reconocimiento tácito que se hace en el periodo anterior al investigado, a partir de su ubicación en los artículos $8^{\circ}$ y 25, en relación al artículo 1.1 de la CADH, con el magistrado Cançado, después de la salida de éste (año 2006, primer año que abarca nuestro artículo), hay un fuerte desarrollo del contenido de este derecho, que, como ya vimos, nos permitió identificar elementos generales y específicos del derecho de acceso a la justicia.

En este segundo período analizado, el desarrollo del derecho de acceso a la justicia se realiza de forma más concreta. Así, aparecen las referencias a las leyes de autoamnistía como incompatibles con la $\mathrm{CADH}^{80}$, lo que debemos ubicar dentro de esta idea general de impedir la impunidad, que lleva también al deber jurídico de obrar de oficio por parte de las autoridades judiciales, para evitar que se pierdan o desaparezcan rastros o evidencias de los crímenes, como también a la idea de proteger a víctimas, familiares y testigos para evitar represalias.

Otro factor que favorece la impunidad, y con ello la denegación del derecho de acceso a la justicia, son las estructuras de poder de la sociedad que generan impedimentos fácticos y también normativos que deben ser removidos para garantizar el acceso a la justicia.

También se consolida como un elemento importante a considerar la existencia de normas y procedimientos claros con relación a los jueces temporales o provisionales, con el objeto de dar continuidad a la administración de justicia. El juez natural, en un caso de grave violación de los derechos humanos, es el del fuero civil y no el del fuero militar, o de cualquier otro fuero especial.

Por otro lado, se fortalece la idea del derecho a la verdad ${ }^{81}$, lo que significa investigar, saber que pasó, esclarecer los hechos, sancionar y obtener una justa e integral reparación a las víctimas y a sus familias, algo que ya venía del

\footnotetext{
${ }^{80}$ Para Nogueira no sólo son incompatibles con la $\mathrm{CADH}$, sino que tampoco tienen validez a la luz del Derecho Internacional de los Derechos Humanos. Nogueira (2004), p. 157.

${ }^{81}$ Los profesores Juan Carlos Hitters y Oscar Fappiano resaltan el reconocimiento del derecho a la verdad, no solo individual, sino que también social. Es decir, no solo la víctima o su familia tiene derecho a saber que pasó, sino que también es la comunidad nacional e internacional la que tiene ese derecho, y señalan que, si bien se trata de un derecho no expresamente reconocido en la $\mathrm{CADH}$, se trata de un derecho que se ha ido desarrollando doctrinal y jurisprudencialmente, y que se encuentra reconocido ya desde los casos "Castillo Páez vs. Perú", del año 1997, y "Bámaca Velásquez vs. Guatemala", del
} 
primer período analizado ${ }^{82}$. Otro tema relacionado es que las familias y las víctimas puedan intervenir tanto en la etapa investigativa como en la judicial (juicio propiamente tal), aportando pruebas, sugiriendo diligencias o, incluso, presentando querellas. El derecho de acceso a la justicia implica el derecho a buscar y a recibir información, lo cual es diferente al derecho a que se investigue.

También se aclara que las comisiones para la verdad no complementan ni menos reemplazan la actividad jurisdiccional del Estado.

En cuanto al recurso efectivo, un elemento nuevo es que esta efectividad debe ser ponderada tomando en cuenta las condiciones generales del país y las particulares del caso, y que exige que la investigación sea diligente, exhaustiva y seria.

Se reitera que la ineficacia judicial constituye en sí una negación de este derecho. En este sentido se plantean defectos de la investigación que hacen deficiente al recurso, como: "i) el manejo de los cadáveres, ii) la ausencia de rigurosidad en la inspección y salvaguarda del lugar de los hechos; iii) el indebido manejo de las evidencias recolectadas y iv) los métodos utilizados que no fueron acordes para preservar la cadena de custodia" ${ }^{83}$.

En otra perspectiva, también las exigencias formales, como hacer una presentación en papel, constituyen un impedimento al acceso a la justicia, si la sanción impuesta no es proporcionada con el derecho vulnerado; la formalidad es secundaria frente a lo importante.

Aparecen más referencias a las víctimas que pertenecen a grupos en situación de vulnerabilidad, quienes resultan discriminados por su situación y, con ello, perjudicados en la igualdad en el ejercicio del derecho de acceso a la justicia; se agrega ${ }^{84}$ a los discapacitados y a sus padres ${ }^{85}$, y a los menores de edad, y se

año 2000. HitTers y FapPiAno (2012a), p. 843; HitTers y FAPPIANo (2012b), p. 1737. El derecho a la verdad ampara tanto a la víctima como a su familia. MinISTERIO PúBLICO FISCAL (2013), p. 35.

${ }^{82}$ Muchas veces aparecen confrontados el derecho a la verdad con el derecho al olvido, pero en materia de violaciones a los derechos humanos debemos recordar que, como expresa Carlos Rúa, "una cosa es el olvido, como derecho de la víctima a no recordar la vulneración de derechos padecida y otra es el olvido como acto de amnesia de las sociedades para evitar aceptar una historia vergonzosa o dolorosa". RuA (2016), p. 472.

${ }^{83}$ Caso Desaparecidos del Palacio de Justicia.

${ }^{84}$ En la primera parte analizada había referencias a los siguientes grupos en situación de vulnerabilidad: las mujeres, los inmigrantes, las comunidades indígenas y quienes se encuentran en situación de pobreza.

${ }^{85}$ Con relación a esta materia, hay mucho por hacer. Larson señala que existe un alentador avance para las personas con discapacidad, pero hay una variedad tan infinita de discapacidades como personas con discapacidad, la que se exige no sólo capacitar a los defensores, sino también a los mismos discapacitados para que puedan hacer valer sus derechos. La tecnología puede ayudar, y mucho, pero se requiere que ella sea accesible también a las personas con discapacidades, lo que hoy no siempre ocurre. Por ello, hay que enfocarse en el individuo antes que nada. LARSON (2014), p. 232. 
señala que el Estado debe adoptar todas las medidas legislativas, sociales, educativas, laborales y de cualquier otra índole para eliminar esa discriminación.

Particularmente en el caso de los discapacitados, la evaluación de la violación del derecho de acceso a la justicia debe hacerse con relación a la afectación que se hace de su familia, ya que esta altera su rutina y opciones para atender al discapacitado. También existe una referencia, en la labor del Estado, a superar las dificultades que genera la pobreza estructural ${ }^{86}$.

En este último sentido, cuando hay discriminación, por género, por ejemplo, la investigación de los hechos denunciados no puede hacerse bajo la misma óptica de cualquier procedimiento; ella debe ser hecha bajo la perspectiva de género, lo que impone el deber de realizarla con todas las consideraciones necesarias del grupo en situación de vulnerabilidad de que se trate, para lo cual hay normas y protocolos, a nivel internacional y seguramente local también.

Plantea que el derecho de acceso a la justicia no es absoluto y, por ende, las tasas judiciales no están prohibidas, sin perjuicio de que ellas sí podrían vulnerar el acceso a la justicia cuando dicho pago supone una negación del acceso a la justicia; por lo anterior, se pueden establecer, pero con las ponderaciones necesarias y proporcionales ${ }^{87}$, para que, en sí, no impidan el acceso en general y existan remedios para los casos particulares en que cualquier tasa sea impeditiva.

Se habla de los principios de subsidiaridad y complementariedad para que, una vez agotados los recursos internos, se pueda recurrir al ámbito internacional y se asegure de esa forma el derecho de acceso a la justicia.

Los fallos deben ser cumplidos de forma íntegra y oportuna, por lo que cualquier normativa "... que contenga una prohibición de impugnar los eventuales efectos de su aplicación o interpretación no puede ser considerada en una sociedad democrática como una limitación válida al derecho a un real y efectivo acceso a la justicia de los destinatarios de esa normativa" ${ }^{\prime \prime 8}$. Además, constituye exigencia del derecho de acceso a la justicia el fundamentar adecuadamente los fallos, debiendo estos dar respuestas reparatorias y no meramente simbólicas, para lo cual la respuesta del Estado debe ser proporcionada al daño

\footnotetext{
${ }^{86}$ Caso Trabajadores de la Hacienda Brasil Verde contra Brasil, voto razonado de Juez Ferrer Mac-Gregor.

${ }^{87}$ Todo sin perjuicio de las preocupaciones y peligros que observa Alexander Aleinikoff, en general, respecto de la ponderación y el principio de la proporcionalidad al analizar los conflictos que se producen en materia de derechos fundamentales, que si bien estimamos deben ser consideradas, de todas formas, y al menos por ahora, constituyen la mejor fórmula para enfrentar y solucionar los conflictos entre derechos fundamentales. AleINIKOFF (2015), pp. 19-55 y 113-131.

${ }^{88}$ Caso Canales Huapaya contra Perú.
} 
causado a la víctima y su repercusión en la sociedad, de manera que no sea un signo de impunidad ${ }^{89}$.

Finalmente, se exige, en la labor del juez, hacer el control de convencionalidad.

De esta forma, queda establecido, en un amplio sentido, el contenido de los estándares del acceso a la justicia en la jurisprudencia de la Corte IDH.

\section{Conclusiones}

En el período objeto de nuestro estudio se dictaron ochenta y nueve sentencias en las cuales se utilizó la expresión "acceso a la justicia" o "derecho de acceso a la justicia", cada una de las cuales fue aportando elementos que, conforme a los principios de progresividad y favor persona, fueron dando contenido concreto al derecho de acceso a la justicia, el cual partió con los votos de minoría, que luego se transformaron en la opinión de la Corte IDH, incluso más allá de la permanencia de los magistrados que promovieron el desarrollo de este derecho fundamental ${ }^{90}$.Así, respondemos a la pregunta inicial señalando, en primer término, que el derecho de acceso a la justicia sí tiene un reconocimiento formal y expreso en la jurisprudencia de la Corte IDH; se lo considera un derecho autónomo e independiente del derecho al debido proceso, cualquiera sea la denominación que se le quiera dar a éste, y el fundamento normativo que se le asigna a este derecho está en los artículos 8.1 y 25, con relación al artículo 1.1 de la $\mathrm{CADH}^{91}$, dotándolo de un rico contenido con amplia implicancia.

De esta forma, el derecho de acceso a la justicia no sólo es exigible en el ámbito de la jurisdicción penal, sino que lo es para todas las materias, como el administrativo o el legislativo, ya que todo procedimiento que busque la determinación o titularidad de un derecho debe ser resuelto con criterios de justicia, y el órgano legislativo debe ejercer su potestad respetando los criterios y valores constitucionales, donde el acceso a la justicia se alza como un derecho fundamental, y por lo tanto inviolable, correspondiéndole al Estado resguardar y garantizar este derecho.

Asimismo, como derecho fundamental, exige que la investigación sea oportuna y la sentencia sea debidamente motivada o razonada; que las medidas que se adopten sean proporcionales al hecho investigado o denunciado, y que se cumpla de manera efectiva. Para ello el recurso debe ser efectivo en un sentido

\footnotetext{
${ }^{89}$ Esta consideración aparece en el Caso García Ibarra y Otros contra Ecuador.

90 Sin duda el magistrado Cançado es el principal promotor, al que luego se sumaron los magistrados García y Ferrer y, en mucho menor medida, los magistrados Ventura, García-Sayán, De Figueiredo, Espinoza y Sierra.

${ }^{91}$ Esto ya se aprecia desde el primer fallo analizado, la sentencia Corte IDH "La Masacre de Pueblo Bello vs. Colombia", 31 de enero de 2006, C 212.
} 
sustantivo; es decir, debe eliminarse toda barrera u obstáculo que impida ejercer con total libertad el derecho al acceso a la justicia, privilegiando la informalidad de la investigación y, en general, evitando la impunidad.

Por otro lado, el derecho de acceso a la justicia se configura como un derecho independiente del debido proceso; éste es un derecho que dice relación con las garantías procesales para que las partes en el procedimiento, o la investigación, ante los tribunales de justicia, gocen de todos los requisitos para asegurar un resultado justo. El acceso a la justicia se vincula con el debido proceso como también con la ejecución de la sentencia y, en general, con las condiciones para acceder a la justicia en circunstancias de igualdad material.

En cuanto a los criterios particulares, debe señalarse que, como derecho fundamental en materia de violaciones a los derechos humanos, es un derecho que abarca otros derechos, como el derecho a conocer la verdad ${ }^{92}$; el derecho a que se investigue ${ }^{93}$ y que se permita la participación de la víctima y sus familias en dicha investigación; a conocer quiénes son los responsables y que se les sancione efectivamente ${ }^{94}$, y a que se repare integralmente al daño causado.

Las investigaciones deben ser en plazo razonable, lo que implica ponderar la complejidad del caso, la actividad de los interesados, la actividad de la autoridad judicial y la afectación de los intereses del afectado causada por la duración del proceso.

En el caso de las desapariciones forzosas, se requiere saber que pasó y dónde están los cuerpos.

El acceso a la justicia debe ser asegurado en condiciones de igualdad a todas las personas, para lo cual debe tomarse en consideración todas aquellas situaciones que puedan provocar un estado de vulnerabilidad de los afectados $^{95}$; así, son grupos en situación de vulnerabilidad los que son afectados por

\footnotetext{
${ }_{92}$ La verdad debe ser establecida por los órganos jurisdiccionales; las comisiones para la verdad ayudan, pero no reemplazan la verdad obtenida jurisdiccionalmente.

${ }^{93}$ La investigación, para cumplir con los estándares mínimos, debe ser diligente, seria y efectiva; así lo señala la Corte IDH en el Caso Defensor de Derechos Humanos, 28 de agosto de 2014, C 242.

${ }_{94}$ Cualquier acto que permita la impunidad de los crímenes de lesa humanidad, en cualquier tópico, atenta contra el acceso a la justicia, como las normas de prescripción, las leyes de autoamnistía y la excepción de cosa juzgada.

95 Sobre este punto, existe, por ejemplo, en el ámbito de las personas en situación de discapacidad, lo que se denomina "ajustes razonables", los que se hacen necesarios cuando una "norma o política, sin ser en su origen discriminatoria, aplicada a una situación específica en el cual el destinatario de la misma es una persona en situación de discapacidad deviene injusta y contraria al principio de igualdad material". FinsteRbusCh (2016), p. 227.
} 
razones de discriminación por género, los inmigrantes ${ }^{96}$, las minorías sexuales, las víctimas de la violencia sexual, los pueblos originarios ${ }^{97}$ o indígenas ${ }^{98}$, las víctimas de la violencia política, los discapacitados ${ }^{99}$, los pobres ${ }^{100}$, siendo vital la asistencia letrada gratuita en todas las etapas de la investigación o proceso, reiterando que es deber del Estado procurarla a quienes no la tienen ${ }^{101}$. De esta forma, hemos expresado cuál es el contenido mínimo reconocido por la jurisprudencia de la Corte IDH, el que debe considerarse por los principales

\begin{abstract}
${ }^{96}$ No podemos, en esta materia, olvidar el derecho de los apátridas, artículo 16 de la Convención sobre el Estatuto de los Apátridas de 1954, en el cual no sólo se extiende al acceso a los tribunales, también la igualdad de trato y la asistencia social, entre otros derechos que reconoce. DIARIO OfICIAL (1999), pp. 416 y 417.

${ }^{97}$ La institucionalidad vigente se puede adaptar a ellos, lo que le da mayor efectividad, por ejemplo con la conciliación. Ella, propia de nuestro ordenamiento jurídico, es más efectiva que el proceso en la resolución de sus conflictos. Así lo resalta Lohengri Ascencio, quien enumera diversas ventajas respecto del proceso en materia indígena: rapidez, informalidad de la comparecencia, ahorro de los abogados, citación por vía más expedita conforme a sus realidades geográficas, no hay límites para audiencias de conciliación, no importa el lugar, etc. AsCENCIO (2015), p. 63.

${ }_{98}$ Tomando en cuenta las características propias de dichas comunidades, ponderando los factores económicos y sociales, así como la situación de vulnerabilidad objetiva (educación, salud, economía, etc.) que puedan tener, y cualquier otro factor que pueda producirse con relación al resto de la comunidad nacional, respetando su derecho consuetudinario, sus valores, sus usos y costumbres.
\end{abstract}

99 Por ejemplo, en el ámbito de la Convención Europea de Derechos humanos, de acuerdo con el artículo $9^{\circ}$, las partes en la Convención son requeridas garantizar a las personas con discapacidad, sobre la base de la igualdad con los demás, acceso al entorno físico (ejemplo, edificios), información y comunicación y otros equipos y servicios abiertos al público. Para garantizar este acceso, deben disponible para ellos formas apropiadas de asistencia (incluidas guías, lectores e intérpretes profesionales en lenguaje de señas). La imposibilidad para que un solicitante ingrese físicamente en un tribunal, por ejemplo debido a la movilidad reducida, podría considerarse una violación de derecho de acceso a un tribunal ("L'accessibilité est l'un des principes fondateurs de la CRPD et «une condition préalable essentielle de la jouissance effective par les personnes handicapées, sur la base de l'égalité des différents droits civils, politiques, économiques, sociaux et culturels». Selon l'article 9, les parties à la Convention sont tenues d'assurer aux personnes handicapées, sur la base de l'égalité avec les autres, l'accès à l'environnement physique (par exemple, les bâtiments), à l'information et à la communication ainsi qu'aux autres équipements et services ouverts au public. Aux fins de garantir cette accessibilité, elles doivent mettre à leur disposition des formes d'aide appropriées (notamment des guides, des lecteurs et des interprètes professionnels en langue des signes). L'impossibilité pour un requérant d'entrer physiquement dans un tribunal, par exemple en raison d'une mobilité réduite, pourrait être considérée comme une violation du droit d'accès à un tribunal..."). European Union Agency For Fundamental Rights (2016), p. 169.

100 La más antigua de las instituciones de acceso a la justicia es la asistencia letrada gratuita, lo que hoy no debiera constituir problema por la gran cantidad de abogados que existen, aunque no puede dejar de recordarse lo que señalaba el profesor Calamandrei: "Muchos abogados, pero poca justicia". Calamandrei (1960), p. 134.

101 Y tampoco pueden ser afectados bajo estados de emergencia o excepción constitucional, como expresa el profesor Justiniano, donde, en la emergencia, la interpretación y aplicación de la norma debe tener presente la tutela efectiva de los derechos fundamentales. Justiniano (2010), p. 284. 
órganos de Chile en materia de reconocimiento y protección de derechos fundamentales, en particular del derecho de acceso a la justicia, en cuanto exigencia de un derecho que tiene el carácter de fundamental.

\section{BiBLIOGRAFIA}

Ahrens, Helen; Rojas Aravena, Francisco, y Sainz Borgo, Juan Carlos (2015): El acceso a la justicia en América Latina: Retos y desafíos (San José de Costa Rica, Impreso por Perspectiva Digital S.A.).

AleiniKoff, Alexander (2015): El derecho constitucional en la era de la ponderación (Perú, Palestra Editores).

Arias Ospina, Felipe, y Galindo Villarreal, Juliana (2015): "El sistema interamericano de derechos humanos", en: Lopez, Luis, y Saiz, Alejandro (directores), Los sistemas interamericano y europeo de protección de los derechos humanos. Una introducción desde la perspectiva del diálogo entre tribunales (Lima, Palestra Editores), pp. 131-164.

AsCENCIO Grez, Lohengri (2015): La conciliación en las comunidades mapuches de la Región de La Araucanía (Chile, Puerto Editores).

Barbero, Natalia (2016): Protección internacional de los Derechos Humanos (Argentina, Rubinzal Culzoni Editores). Tomo IV.

Bordalí Salamanca, Andrés (2011): "Análisis crítico de la jurisprudencia del Tribunal Constitucional sobre el derecho a la tutela judicial", en: Revista Chilena de Derecho (Vol. 38, № 2), pp. 311-337.

(2016): Derecho jurisdiccional (Valdivia, Editorial Derecho Austral).

CalabriA, Daniel, y Perrone, Nicolás (2006): “Estado, acceso a la justicia y sociedad. Una visión totalizadora", en: Brenna, Ramón (director), Acceso a la justicia: Trabajos del concurso Argenjus 2005 (Buenos Aires, Editorial La Ley), pp. 1-46

Calamandrel, Piero (1960): Demasiados abogados (Traducc. Santiago Sentís, Buenos Aires, Ediciones Jurídicas Europa-América, EJEA).

Cançado Trindade, Antonio (2012): El derecho de acceso a la justicia en su amplia dimensión (Santiago de Chile, Editorial Librotecnia).

(2013): El principio básico de igualdad y no discriminación: Construcción jurisprudencial (Santiago de Chile, Editorial Librotecnia).

CANESSA, Jorge (2014): El Sistema Interamericano de Derechos Humanos y la protección de los derechos humanos laborales (Perú, Palestra Editores).

Cappelletti, Mauro, y Garth, Bryant (1983): El acceso a la justicia (Traducc. de Samuel Amaral, Buenos Aires, Impreso en Gráfica Pafernol). 
Corte Interamericana de Derechos Humanos (1999): "Opinión Consultiva OC 16/99, de 1 de octubre de 1999, sobre el Derecho a la Información sobre la Asistencia Consular en el Marco de las Garantías del Debido Proceso Legal, solicitada por los Estados Unidos Mexicanos". Disponible en: http://www. corteidh.or.cr/docs/opiniones/seriea_16_esp.pdf [visitado el 6.09.2017].

(2018): "Jurisprudencia de la Corte Interamericana de Derechos Humanos". Disponible en: http://www.corteidh.or.cr/index.php/jurisprudencia [visitado el 15.10.2018].

CONTESSE SINGH, Jorge (2010): "Sistema Interamericano de Derechos Humanos y paridad de participación: El progreso constitucional desde afuera", en: Cazor, Kamel, y Salas, Carolina (coordinadores), Estudios Constitucionales (Santiago, Librotecnia/Asociación Chilena de Derecho Constitucional), pp. 169-203.

Díaz Cornejo, María Soledad (2006): "Hacia un enfoque integral del acceso a la justicia. La situación en la provincia de Córdoba", en: Brenna, Ramón (director), Acceso a la justicia: Trabajos del concurso Argenjus 2005 (Buenos Aires, Editorial La Ley), pp. 155-214.

Díaz García, Luis Iván, y UrzúA Gacitúa, Patricia (2018): "Procedimientos administrativos disciplinarios en Chile. Una regulación vulneradora del derecho fundamental al debido proceso", en: Revista lus et Praxis (Año 24, № 2), pp. 183-222.

Espejo Yaksic, Nicolás, y Leiva García, Carla (2012): Digesto de jurisprudencia de la Corte Interamericana de Derechos Humanos (Santiago, LegalPublishing Chile y Thomson Reuters).

European Union Agency For Fundamental Rights (2016): "Manuel de droit européen en matiére d'accés á la justice". Disponible en : http://fra.europa.eu/ fr/publication/2016/manuel-de-droit-europeen-en-matiere-dacces-la-justice [visitado el 20.11.2017].

Finsterbusch Romero, Christian (2016): "La extensión de los ajustes razonables en el derecho de las personas en situación de discapacidad de acuerdo al enfoque social de los derechos humanos" en: Revista lus et Praxis (Año 22, $N^{\circ}$ 2), pp. 227-252.

García Ramírez, Sergio (2012): El debido proceso. Criterios de la jurisprudencia interamericana (México, Editorial Porrúa).

Gómez LaRa, Cipriano (2006): "El debido proceso como derecho humano", en: González Martin, Nuria (coordinadora), Estudios jurídicos en homenaje a Marta Morineau (México, Instituto de Investigaciones Jurídicas, UNAM), pp. 341-358. 
Gozaínı, Osvaldo (2006): Introducción al Derecho Procesal Constitucional (Santa Fe, Editorial Rubinzal- Culzoni).

(2016): El Sistema Procesal Interamericano (Argentina, Editora Ar, Ediar).

GreIF, Jaime (2014): I. Quo vadis Justitia? II. Acceso a la justicia (La Plata, Librería Editora Platense SRL).

Hitters, Juan Carlos, y FAPPIANo, Óscar (2012): Derecho Internacional de los Derechos Humanos (Buenos Aires, Editorial Ediar), tomo II, volumen 2.

HitTers, Juan Carlos, y FappiAno, Óscar (2012): Derecho Internacional de los Derechos Humanos (Buenos Aires, Editorial Ediar), tomo II, volumen 3.

IBÁÑez Rivas, Juana María (2014): "Artículo 8. Garantías judiciales", en: Steiner, Christian, y Uribe, Patricia (editores), Convención Americana sobre Derechos Humanos. Comentario (Santiago, Fundación Konrad Adenauer Stiftung), pp. 207-254.

Justiniano Robledo, Federico (2010): "Las Garantías judiciales como vías de tutela de los derechos fundamentales en estados de emergencia (in) constitucional", en: Revista del Centro de Estudios Constitucionales (Año 8, No 2), pp. 247-292.

LARRANDART, Lucila (2016): Memoria, verdad y justicia (Buenos aires, Editorial Hammurabi).

LARSEN, Pablo (2016): Jurisprudencia de la Corte Interamericana de Derechos Humanos (Buenos Aires, Editorial Hammurabi SRL).

LARSON, David Allen (2014): "Access to justice for Persons with Disabilities: An Emerging Strategy". Disponible en: https://papers.ssrn.com/sol3/papers. cfm?abstract_id=2442534 [visitado el 20.10.2017].

Marabotto Lugaro, Jorge (2003): "Un derecho humano esencial: El acceso a la justicia", en: Anuario de Derecho Constitucional Latinoamericano (edición 2003), pp. 291-301.

Maurino, Gustavo (2016): "Los procesos colectivos", en: Gargarella, Roberto, y Guidi, Sebastián (coordinadores), Comentarios de la Constitución de la Nación Argentina (Argentina, Editorial La Ley SAE e I), tomo II, pp. 871-965.

Ministerio Público Fiscal de la Ciudad Autónoma de Buenos Aires (2013): El debido proceso legal: Análisis desde el sistema interamericano y universal de derechos humanos (Buenos Aires, Editorial Eudeba), tomo II.

Nogueira AlcalÁ, Humberto (2004): "Elementos del bloque constitucional del acceso a la jurisdicción y debido proceso proveniente de la Convención Americana de Derechos Humanos", en: Revista Centro de Estudios Constitucionales (Año 2, No 1), pp. 123-158. 
(2008): Derechos fundamentales y garantías constitucionales (Santiago, Editorial Librotecnia), tomo 2.

(2012): El debido proceso en la Constitución y el sistema interamericano, segunda edición (Santiago, Editado por Librotecnia).

PitA, Enrique Máximo (2016): "Derecho a un proceso sin dilaciones indebidas", en: Priori Posada, Giovanni (coordinador), Constitución, derecho y derechos. Libro de ponencias del Primer Encuentro de la Red Justicia (Lima, Palestra Editores), pp. 165-172.

Rojas Franco, Enrique (2011): "El debido proceso administrativo", en: Revista de la Facultad de Derecho de la P. Universidad Católica del Perú ( No $^{\circ}$ 67), pp. 177-188.

Rúa Delgado, Carlos (2016): “La justicia anamnética como construcción complementaria del paradigma de justicia transicional. Una mirada desde el caso colombiano", en: Revista lus et Praxis (Año 22, No 1), pp. 455-492.

Secretaría Nacional de Educación Superior de Ecuador (2008): "Constitución Política de la República del Ecuador". Disponible en: http://www.produccion. gob.ec/wp-content/uploads/downloads/2012/07/Normas_Constitucionales. pdf [visitado el 1.10.2016].

Vallespín Përez, David (2002): El modelo constitucional de juicio justo en el ámbito del proceso civil (Barcelona, Editorial Atelier).

\section{JURISPRUDENCIA CITADA}

Sentencia caso "Niños de la Calle (Villagrán Morales y otros) vs. Guatemala" (1999), Corte IDH, de 19 de noviembre 1999. Disponible en: http://www.corteidh.or.cr/docs/casos/articulos/Seriec_63_esp.pdf [visitado el 21.03.2017].

Sentencia caso "Durand y Ugarte vs. Perú" (2000), Corte IDH, de 16 de agosto 2000. Disponible en: http://www.corteidh.or.cr/docs/casos/articulos/ Seriec_68_esp.pdf [visitado el 21.05.2017].

Sentencia caso "Bámaca Velásquez vs. Guatemala" (2000), Corte IDH, de 25 de noviembre 2000. Disponible en: http://www.corteidh.or.cr/docs/casos/ articulos/Seriec_70_esp.pdf [visitado el 22.04.2017].

Sentencia caso "Hilaire, Constantine y Benjamín y otros vs. Trinidad y Tobago" (2002), Corte IDH, de 21 de junio 2002. Disponible en: http://www.corteidh. or.cr/docs/casos/articulos/Seriec_94_esp.pdf [visitado el 4.05.2017].

Sentencia caso "Cantos vs. Argentina" (2002), Corte IDH, de 28 de noviembre de 2002. Disponible en: http://www.corteidh.or.cr/docs/casos/articulos/ seriec_97_esp.pdf [visitado el 2.09.2017]. 
Sentencia caso "Juan Humberto Sánchez versus Honduras" (2003), Corte IDH, de 7 de junio de 2003. Disponible en: http://www.corteidh.or.cr/docs/casos/ articulos/seriec_99_esp.pdf [visitado el 1.09.2017].

Sentencia caso "Bulacio con Argentina" (2003), Corte IDH, de 18 de septiembre de 2003. Disponible en: http://www.corteidh.or.cr/docs/casos/articulos/ seriec_100_esp.pdf [visitado el 1.09.2017].

Sentencia caso "Myrna Mack Chang vs. Guatemala" (2003), Corte IDH, de 25 de noviembre 2003. Disponible en: http://www.corteidh.or.cr/docs/casos/ articulos/seriec_101_esp.pdf [visitado el 2.06.2017].

Sentencia (competencia) caso "Baena Ricardo y otros vs. Panamá" (2003), Corte IDH, de 28 de noviembre de 2003. Disponible en: http://www.corteidh.or.cr/ docs/casos/articulos/seriec_104_esp.pdf [visitado el 4.09.2017].

Sentencia caso "19 Comerciantes vs. Colombia" (2004), Corte IDH, de 5 de julio de 2004. Disponible en: http://www.corteidh.or.cr/docs/casos/articulos/ seriec_109_esp.pdf [visitado el 7.09.2017].

Sentencia caso "Hermanos Gómez Paquiyauri vs. Perú" (2004), Corte IDH, de 8 de julio 2004. Disponible en: http://www.corteidh.or.cr/docs/casos/articulos/ seriec_110_esp.pdf [visitado el 6.02.2017].

Sentencia caso "Comunidad Moiwana vs. Suriname" (2005), Corte IDH, de 15 de junio de 2005. Disponible en: http://www.corteidh.or.cr/docs/casos/ articulos/seriec_124_esp1.pdf [visitado el 8.09.2017].

Sentencia caso "Masacre de Mapiripán vs. Colombia" (2005), Corte IDH, de 15 septiembre de 2005. Disponible en: http://www.corteidh.or.cr/docs/casos/ articulos/seriec_134_esp.pdf [visitado el 25.01.2017].

Sentencia caso "La Masacre de Pueblo Bello vs. Colombia" (2006), Corte IDH, de 31 de enero de 2006. Disponible en: http://www.corteidh.or.cr/docs/ casos/articulos/seriec_140_esp.pdf [visitado el 12.09.2017].

Sentencia caso "Palamara contra Chile" (2006), Corte IDH, de 22 de noviembre de 2006. Disponible en: http://www.corteidh.or.cr/docs/casos/articulos/ seriec_135_esp.pdf [visitado el 24.03.2016].

Sentencia caso "Trabajadores Cesados del Congreso (Aguado Alfaro y otros) vs. Perú" (2006), Corte IDH, de 24 noviembre de 2006. Disponible en: http:// www.corteidh.or.cr/docs/casos/articulos/seriec_158_esp.pdf [visitado el 1.06.2017].

Sentencia caso "Radilla Pacheco vs. Estados Unidos Mexicanos" (2009), Corte IDH, de 23 de noviembre de 2009. Disponible en: http://www.corteidh.or.cr/ docs/casos/articulos/seriec_209_esp.pdf [visitado el 24.07.2017]. 
Sentencia caso "Fernández Ortega y Otros vs. México" (2010), Corte IDH, de 30 de agosto de 2010. Disponible en: http://www.corteidh.or.cr/docs/casos/ articulos/seriec_215_esp.pdf [visitado el 20.07.2017].

Sentencia caso "Mohamed vs. Argentina" (2012), Corte IDH, de 23 de noviembre de 2012. Disponible en: http://www.corteidh.or.cr/docs/casos/articulos/ seriec_255_esp.pdf [visitado el 3.09.2017].

Sentencia caso "Canales Huapaya y Otros vs. Perú" (2015), Corte IDH, de 24 de junio de 2015. Disponible en: http://www.corteidh.or.cr/docs/casos/ articulos/seriec_296_esp.pdf [visitado el 15.08.2017].

Sentencia caso "Defensor de Derechos Humanos y Otros vs. Guatemala" (2014), Corte IDH, de 28 de agosto de 2014. Disponible en: http://www.corteidh. or.cr/docs/casos/articulos/seriec_283_esp.pdf [visitado el 19.08.2017].

Sentencia caso "Rodríguez Vera y Otros (Desaparecidos del Palacio de Justicia) vs. Colombia" (2014), Corte IDH, de 14 de noviembre de 2014. Disponible en: http://www.corteidh.or.cr/docs/casos/articulos/seriec_287_esp.pdf [visitado el 12.10.2017].

Sentencia caso "García Ibarra y Otros vs. Ecuador" (2015), Corte IDH, de 17 de noviembre de 2015. Disponible en: http://www.corteidh.or.cr/docs/casos/ articulos/seriec_306_esp.pdf [visitado el 18.08.2017].

Sentencia caso "Trabajadores de la Hacienda Brasil Verde vs. Brasil" (2016), Corte IDH, de 20 de octubre de 2016. Disponible en: http://www.corteidh. or.cr/docs/casos/articulos/seriec_318_esp.pdf [visitado el 5.09.2017]. 
